\title{
Stage III Penile Cancer AJCC v8
}

National Cancer Institute

\section{Source}

National Cancer Institute. Stage III Penile Cancer A/CC v8. NCI Thesaurus. Code C140084.

Stage III includes: IIIA: T1-3, N1, M0; IIIB: T1-3, N2, M0. T1: Glans: Penile cancer with tumor invading lamina propria. Foreskin: Penile cancer with tumor invading dermis, lamina propria, or dartos fascia. Shaft: Penile cancer with tumor invading connective tissue between epidermis and corpora regardless of location. All sites with or without lymphovascular invasion or perineural invasion and is or is not high grade. T2: Penile cancer with tumor invading into corpus spongiosum (either glans or ventral shaft) with or without urethral invasion. T3: Penile cancer with tumor invading into corpora cavernosum (including tunica albuginea) with or without urethral invasion. N1: Penile cancer with two or less unilateral inguinal metastases, no extranodal extension. N2: Penile cancer with three or more unilateral inguinal metastases or bilateral metastases. M0: No distant metastasis. (AJCC 8th ed.) 